\title{
A Novel Method for Dengue Management Based on Vital Signs and Blood Profile
}

\author{
S.H.U.Briyatis, S. C. Premaratne, D.G.Harendra De Silva
}

\begin{abstract}
Dengue a mosquito-borne viral disease has become a significant cause of morbidity and mortality in Sri Lanka over the past few years. Based on the symptoms signs and investigations, dengue can be classified as Dengue Fever (DF), Dengue Hemorrhagic Fever (DHF) and Dengue Shock Syndrome (DSS). Since it is a viral infection, medications have not been developed yet. Attempts to develop a vaccine in the prevention has not been completed yet. Our research is based on Cased-Based Reasoning (CBR) to develop an Online decision support system to manage dengue illness. CBR is one method that is capable of reasoning or solving problems on a case that has existed as a solution to a new problem. The CBR system identified the most critical vital signs, parameters, and investigations in different possible situations in DHF and DSS and designed six distinct cases. Clinical parameters and values or ranges of those parameters are used for this research with the guidance of Physicians. The system is developed based on index cases and rules. The system will predict the current situation of the patient by analyzing his/her past and present vital signs and investigations. Usually, $\mathrm{DHF}$ patients are monitored hourly, and important monitoring parameters will be entered into the system. The system will then display the current clinical stage and impending issues. Suggestions in the management are indicated. Using this system medical personnel can see how is the Pulse Pressure, Urine Output, Packed Cell Volume (PCV), Platelet Count and White Cell Count (WCC) vary according to the clinical stage of a particular patient. The evaluation of the system was carried out using some past cases of dengue in different stages. Our result shows that the CBR approach can gain significant accuracy in dengue management.
\end{abstract}

Index Terms: Decision support system, case-based reasoning $(C B R)$, machine learning, Prediction.

\section{INTRODUCTION}

Dengue is one of the most rapidly spreading mosquito-borne viral infections endemic in tropical and sub-tropical regions around the world. Infection of Dengue fever is caused by female mosquitoes mainly of the species Aedes Egypti and Albopictus. In the first half of 2017 alone, 80732 dengue cases, with 215 Dengue deaths were accounted for in Sri Lanka [1].

Dengue virus infections may be asymptomatic or may lead to undifferentiated fever, dengue fever (DF) or Dengue Hemorrhagic fever (DHF) with plasma leakage that may lead to Dengue shock syndrome (DSS) [2].

The general behavior of dengue infection is as described below. Assume the 10,000 people have dengue infection. Out of the 9,000 people belong to Asymptomatic group. They do

\section{Revised Manuscript Received on September 22, 2019.}

S. H. U. Briyatis, Faculty of Information Technology, University of Moratuwa.

S. C. Premaratne, Faculty of Information Technology, University of Moratuwa.

D. G. Harendra De Silva, Department of Paediatrics, Faculty of Medicine, University of Colombo. not have a fever and syndrome. However, they have dengue virus and spread the dengue virus to others. Five hundred from the remaining 1,000 have a viral fever with decreasing White Cell Count (WCC) and normal platelet count. After one week, still, they doubt Dengue, or NS1 antigen is positive do antibodies. Four hundred from the remaining 500 have Dengue Fever with decreasing White Cell Count (WCC) and decreasing Platelet count but no leakage[3]. The remaining 100 have DHF with leakage. During this research mainly focused on DHF patients whose NS1 antigen is positive.

In some cases, Dengue is an asymptomatic (Fig. 1). It does not mean that people do not show symptoms. For those who have symptoms, pain occurs between 4 to 7 days of bites. This infection is caused by the onset of symptoms of the virus, sudden fever of the waves, eyes, muscles, joints and bone pain, headache, and redness of the skin. Supportive care includes symptoms. Antibiotics cannot be treated.

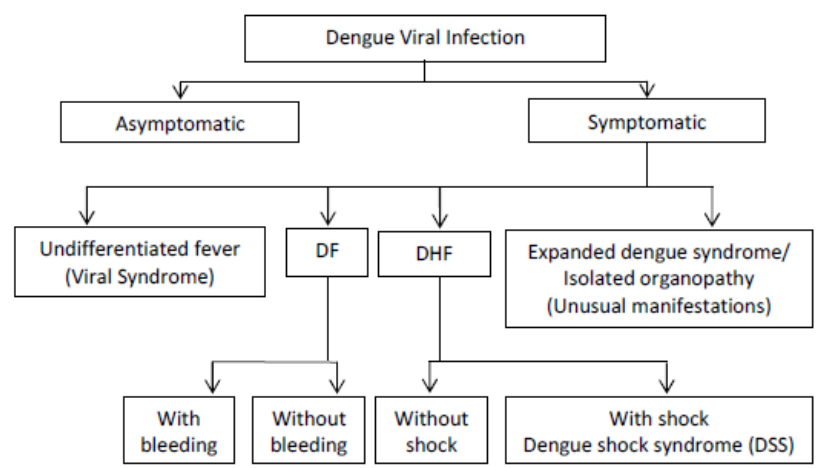

Fig. 1: Manifestation of dengue virus infection

The fever takes about 4-7 days, and with the settlement of the temperature, many patients are healed without complications. However, some people go on to develop severe complications within 48 hours around the critical stage of the plasma leak.

After the period of the incubation, the disease starts suddenly and then takes place in three stages: febrile, critical and recovery stage Fig. 2. [4]

- Febrile phase: high-grade fever suddenly and usually lasts 2-7 days

- Critical/plasma leak phase: Sudden variation of plasma leakage into the pleural and abdominal cavities

- Recovery phase: During the critical phase between 24-48

hours, plasma
leakage is usually 
exerted and stopped by a highly abnormal reaction

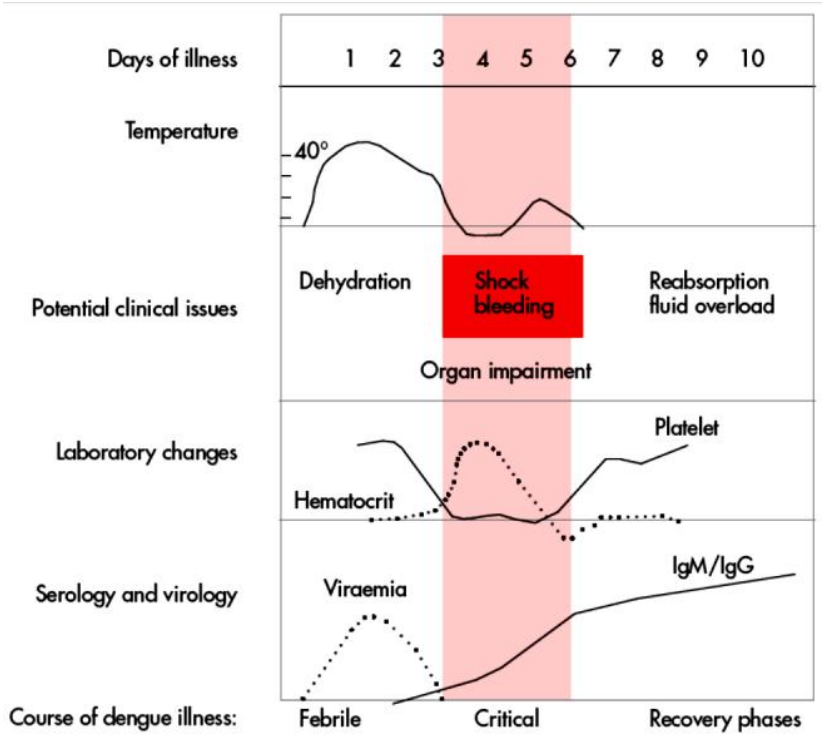

Fig. 2: Course of dengue illness

DF begins with a " febrile line" with the fever. Platelets and white blood cells slowly decrease with blood (blood pressure). After that, the fever has disappeared, and the patient becomes a dengue patient. In this stage, the platelet counts and WBC plunges dramatically while hematocrit is elevated. Symptoms are severe and can cause dehydration and bleeding if the patient is not addressed seriously and promptly, and later susceptible to vomiting and / or death. If the symptoms are minor, the critical stage ends at the 5th or 6th day, the platelets are slowly growing, and the patient is perfectly well [6].

However, often, it is challenging to differentiate DF from DHF in the early phase (febrile phase) of disease. When there is a high fever in DHF, it is associated with symptoms in DF at the early febrile stage. Plasma leak is a distinctive sign of DHF that occurs after the febrile stage ends. There is a tendency of developing DSS due to plasma leakage. Therefore, DF and DHF patients should be closely monitored to identify patients with DHF. The rate of plasma bleeding in DHF may vary. Some patients may be infinite, while others are significant. The leak usually begins gradually and gradually increases, slows down, and finally of leakage phase (usually within 48 hours) [2].

The main factors and blood profiles associated with dengue are blood pressure (BP), heart rate (HR), body temperature $(\mathrm{BT})$, packaged cell volume $(\mathrm{PCV})$, platelets (PLT), white blood cells (WBC), urine output and fluid intake rate [5]. Hematocrit (HCT), Platelet (PLT), and Whole Blood Cells (WBCs) are all components of the whole blood test. Dengue virus infected person suffers from high fever. The WHO notes that dengue fever (DF), dengue hemorrhagic fever (DHF) and dengue shock syndrome (DSS) that address plasma leakage.

Appropriate medical treatment and disease management can be identified early in the event of dengue shock or severe involvement. For dengue patients, the dengue-management model is essential based on vital signs and blood type. Identifications of most essential cases related Dengue and identification of rules which are related to those cases are helped to develop a system to predict the current situation of the patient by analyzing his/her past vital signs and blood profiles. Table I shows the comparison between the normal and the critical ranges of the essential parameters to this research.

Table I: Comparison between important parameters

\begin{tabular}{|c|c|c|}
\hline Parameter & Normal Range & $\begin{array}{c}\text { Critical } \\
\text { Stage }\end{array}$ \\
\hline $\begin{array}{c}\text { Blood } \\
\text { Pressure } \\
\text { (mmHG) }\end{array}$ & $120 / 80$ & $90 / 60$ \\
\hline Heart Rate & $80-60$ & Above 100 \\
\hline $\begin{array}{l}\text { Temperature } \\
\text { (C) }\end{array}$ & 36.8 & Above 36.8 \\
\hline
\end{tabular}

\section{LITRETURE REVIEW}

Dengue virus can be diagnosed by detection of dengue virus NS1 antigen and immunoglobulin $\mathrm{M}$ ( $\operatorname{IgM}) / \mathrm{IgG}$ antibodies. There is a tool kit called SD Dengue Duo rapid test kit [7]. Dengue virus NS1 antibodies and infrared IgM/ $\mathrm{IgG}$ antibodies have been designed for human consumption. An NS1 antibiotic is usually found from day 1 to day 9 after starting the fever. However, the initial dengue fever can be detected from IgM from 3 days to 5 days, and by Day 1 to Day 2 after the onset of illness in secondary infections. The Dengue Eye Expert Kit is useful for identifying the spread of dengue rapidly. SD Dengue Duo rapid test kit is useful for the rapid, early diagnosis of dengue infections. The current evaluation of the SD Dengue Duo NS1/IgM shows that this assay has a sensitivity of $88.65 \%$ (95\% CI: 84.04-93.26), a specificity of $98.75 \%$ (95\% CI: 96.26-100) with an assay efficiency of $91.70 \%$. By detecting both NS1 and IgM in dengue infection has shown that the SD Dengue Duo rapid test kit is useful, sensitive, and specific for the diagnosis of acute dengue infection[8].

A Preliminary Dengue Fever Prediction Model [9] is used to find the result of the patients' severity of dengue infection. The Matlab's statistical toolbox used the formatting and assumption for a classroom learner. Training models include paint trees, variations analysis, support datasets, logistics recruitment, and neighboring classifications. This model was trained using 30 data from dengue patients. Healing pressure (BP), pulse pressure (PP), HR, BT, HCT, PLT, and finally WBC. The severity is divided into three groups. One is for dengue fever without warning signs (DF). Two is dengue fever with warning signs (DFWS), and three is severe dengue (SD). The user/clinic allows the developed GUI to test the severity of the dengue patient. After entering important GUI tables and entering the values of the blood profile, a response to the classification of the dengue fever response will be addressed. However, the accuracy of the test data was $50 \%$ with a $50 \%$ error. 
Therefore, this method provides low accuracy during verification.

Fuzzy Inference System (FIS) [10] was designed to early diagnosis of dengue disease. The most commonly used artificial intelligence in medicine (AIM) system is that a patient can obtain a definitive conclusion by using certain data. Fuzzy logic builds on human rights rules provided by users. Their designed system is based on the clinical database in South Taiwan's clinical database. This database has resulted in various physical symptoms of the dengue patient and the dengue patient's medical tests. MATLAB's most powerful logical toolbox looked at the eleventh probability variables and one output variant using the logical theoretical toolbox. The decision-making method is useful for dengue fever(DF), Dengue hemorrhagic fever (DHF) and Dengue shock syndrome (DSS) are not classified as risky ones. The inputs parameters of the system's planned inputs are insufficient for that purpose since the input classification is required based on input parameters.

A Belief Rule-based Expert System to Diagnose Dengue Fever under Uncertainty

The system uses a traditional method used for the dengue epidemic, usually not performed by doctors. The standard method of dengue control is HCT, WCC, and blood samples for plucking platelets. Avoiding the risk of dengue fever and avoiding the risk of dengue fever is an aversion to dengue fever. This approach is based on the signs, symptoms and risk factors of dengue fever such as Fever, Headache, Rash, Congested Conjunctiva, Relative Bradycardia, Number of mosquito bites, Mosquito bleeding place and population. This approach is two parts and includes several techniques, based on a reliable policy framework and process mechanism. They have developed the decision tree and help identify the dengue. This approach is a strategic plan to reduce the risk of dengue fever in the context of a country [11].

\section{METHOD}

Case-based reasoning is a general paradigm for reasoning from experience. It assumes a memory model for representing past events, indexing and organizing them. It is a process for the re-acquisition and modernization of old cases. Settlement of new issues will be dealt with by prior codification of the CBR

Successful solutions to similar issues. [12]

CBR working cycle can be described best in terms of four processing stages: [12]

1. Case retrieval: after the problem situation has been assessed, the best matching case is searched in the case base and an approximate solution is retrieved.

2. Case adaptation: the retrieved solution is adapted to fit better the new problem. evaluated either before the solution is applied to the problem or after the solution has been applied. In any case, if the

accomplished result is not satisfactory, the retrieved solution must be adapted again or
3. Solution evaluation: the adapted solution can be

more cases should be retrieved.

4. Case-base updating: If the solution was verified as correct, the new case may be added to the case base.

The CBR process can be defined as a cyclic procedure. The problem has posed a new issue that needs to be addressed in the space. In the first step, by comparing similar problems by reviewing, a new problem can match the previous issues, and the more similar problem and the solution stored there can be found. If the proposed solution meets the need for a new problem situation, the next step is an adaptation, occurrence, and a new solution. A valid solution within a learning step and a new problem build up a new case. Thus, the CBR system becomes a better argument. As the potential of the system has been enhanced by expanding storage experience. [13]

\section{A. Analytic Module}

This module works as Cased Based Reasoning process, analyze the inputs with the previous data and pushed data to database and display suggestions and current phase of Dengue (Fig. 3)

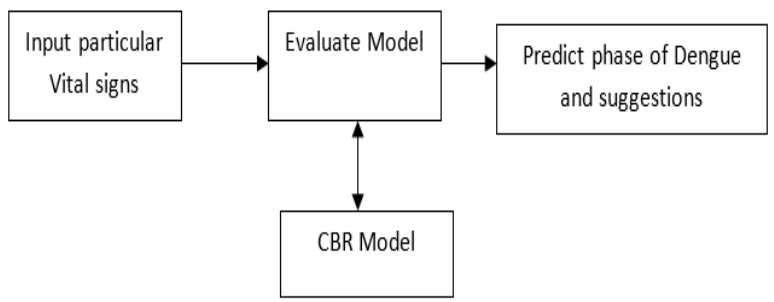

Fig. 3: Analytics module

The initial module is retrieved by using a practical scenario by consulting doctors. This module is consisting of cases and rules for each and every case. Reuse the cases to solve the problem with the known dataset. Cases and rules are revised if necessary and retrain the new module as part of a new case(s) or rule(s). Fig. 4 describes the process of module designing.

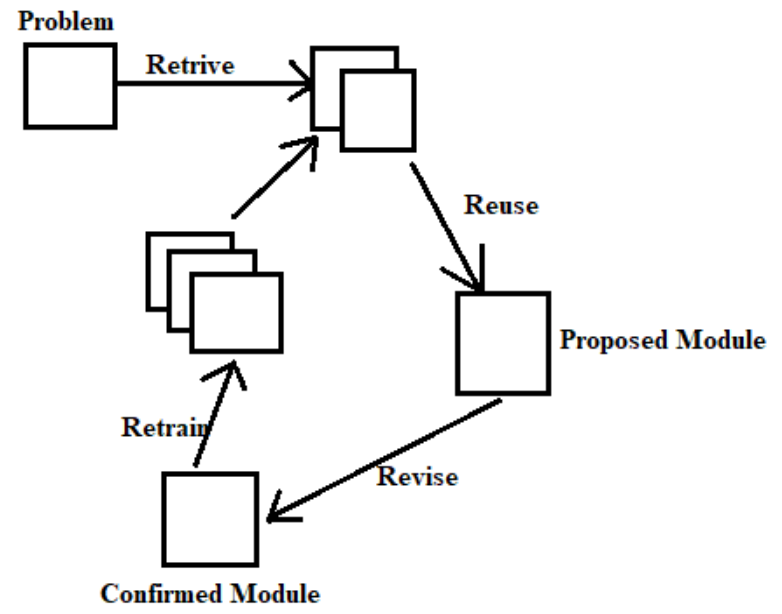

Fig. 4: Process flow of the analytics module 


\section{B. Data Collection}

The records of dengue patients obtained from the Centre for the Clinical Management of Dengue and Dengue Haemorrhagic Fever at District General Hospital, Negombo. Each data set consisted of heart rate, systolic and diastolic blood pressures, pulse pressure, respiratory rate, HCT, platelet count, WCC, Urine Output, and Fluid Intake at each hour. These values were recorded as numeric values. The selected patients included both males and females between 18 to 60 years of age and weighted over $50 \mathrm{~kg}$. These measurements were taken at equally spaced time points (hourly) since the patient was admitted to the hospital. Here we mainly considered the Dengue patients whose NS1 antigen is positive [14].

Initially, the manually recorded data Dengue patients were stored in a spreadsheet (Fig. 5). The most important part of data was preprocessed to determine the best parameters that contribute to the decision-making. The data selection requires some detailed knowledge of the problem and the underlying data. The most sensitive parameters that contribute to the detection of Critical phase are,

- $\quad$ Pulse pressure (mmHg)

- $\quad$ Packed Cell Volume (PCV) (\%)

- Platelet count (x103/uL)

- Urine Output (UOP) $(\mathrm{ml} / \mathrm{kg} / \mathrm{hr})$

- White Cell Count(x103/uL)

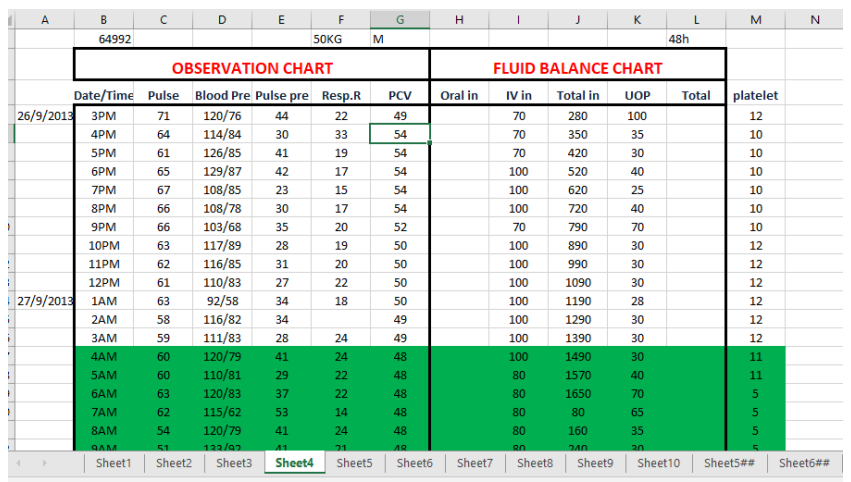

Fig. 5: Sample of the data collection

\section{IMPLEMENTATION OF BACK-END DATA MODULE}

Database of this application has been implemented with MS SQL database technology. Database stores all the of patients' information, vital signs information related to each and every patient [15].

The patient table consists of below fields.

- PatientID - This is the primary key of the table

- Name - Name of the patient

- Dob - Date of birth. This is used to calculate the age of the patient

- Sex - Female or Male

- Height - Height of the patient

- Actual weight - Actual body weight of the patient

- Ideal weight - Ideal body weight of the patient. Ideal body weight is calculated by considering the Height of the patient and the Gender of the patient.

Below chart is used to calculate the Ideal body weight.

\begin{tabular}{|c|c|c|}
\hline & Adults Weight & \\
\hline Height - Ft. In. (cms) & Female & Male \\
\hline $4^{\prime} 6^{\prime \prime}-(137 \mathrm{~cm})$ & $63-77 \mathrm{lb}-(28.5-34.9 \mathrm{~kg})$ & $63-77 \mathrm{lb}-(28.5-34.9 \mathrm{~kg})$ \\
\hline $4^{\prime} 7^{\prime \prime}-(140 \mathrm{~cm})$ & $68-83 \mathrm{lb}-(30.8-37.6 \mathrm{~kg})$ & $68-84 \mathrm{lb}-(30.8-38.1 \mathrm{~kg})$ \\
\hline $4^{\prime} 8^{\prime \prime}-(142 \mathrm{~cm})$ & $72-88 \mathrm{lb}-(32.6-39.9 \mathrm{~kg})$ & $74-90 \mathrm{lb}-(33.5-40.8 \mathrm{~kg})$ \\
\hline $4^{\prime} 9^{\prime \prime}-(145 \mathrm{~cm})$ & $77-94 \mathrm{lb}-(34.9-42.6 \mathrm{~kg})$ & $79-97 \mathrm{lb}-(35.8-43.9 \mathrm{~kg})$ \\
\hline $4^{\prime} 10^{\prime \prime}-(147 \mathrm{~cm})$ & 81 - $99 \mathrm{lb}-(36.4-44.9 \mathrm{~kg})$ & $85-103 \mathrm{lb}-(38.5-46.7 \mathrm{~kg})$ \\
\hline $4^{\prime \prime} 11^{\prime \prime}-(150 \mathrm{~cm})$ & $86-105 \mathrm{lb}-(39-47.6 \mathrm{~kg})$ & $90-110 \mathrm{lb}-(40.8-49.9 \mathrm{~kg})$ \\
\hline $5^{\prime} 0^{\prime \prime}-(152 \mathrm{~cm})$ & $90-110 \mathrm{lb}-(40.8-49.9 \mathrm{~kg})$ & $95-117 \mathrm{lb}-(43.1-53 \mathrm{~kg})$ \\
\hline $5^{\prime} 1^{\prime \prime}-(155 \mathrm{~cm})$ & $95-116 \mathrm{lb}-(43.1-52.6 \mathrm{~kg})$ & $101-123 \mathrm{lb}-(45.8-55.8 \mathrm{~kg})$ \\
\hline $5^{\prime} 2^{\prime \prime}-(157 \mathrm{~cm})$ & 99 - $121 \mathrm{lb}-(44.9-54.9 \mathrm{~kg})$ & $106-130 \mathrm{lb}-(48.1-58.9 \mathrm{~kg})$ \\
\hline $5^{\prime} 3^{\prime \prime}-(160 \mathrm{~cm})$ & $104-127 \mathrm{lb}-(47.2-57.6 \mathrm{~kg})$ & $112-136 \mathrm{lb}-(50.8-61.6 \mathrm{~kg})$ \\
\hline $5^{\prime} 4^{\prime \prime}-(163 \mathrm{~cm})$ & $108-132 \mathrm{lb}-(49-59.9 \mathrm{~kg})$ & $117-143 \mathrm{lb}-(53-64.8 \mathrm{~kg})$ \\
\hline $5^{\prime} 5^{\prime \prime} \cdot(165 \mathrm{~cm})$ & $113-138 \mathrm{lb}-(51.2-62.6 \mathrm{~kg})$ & 122 - $150 \mathrm{lb}-(55.3-68 \mathrm{~kg})$ \\
\hline $5^{\prime} 6^{\prime \prime}-(168 \mathrm{~cm})$ & $117-143 \mathrm{lb}-(53-64.8 \mathrm{~kg})$ & 128 - $156 \mathrm{lb}-(58-70.7 \mathrm{~kg})$ \\
\hline $5^{\prime} 7^{7 \prime}-(170 \mathrm{~cm})$ & $122-149 \mathrm{lb}-(55.3-67.6 \mathrm{~kg})$ & $133-163 \mathrm{lb}-(60.3-73.9 \mathrm{~kg})$ \\
\hline $5^{\prime} 8^{\prime \prime}-(173 \mathrm{~cm})$ & $126-154 \mathrm{lb}-(57.1-69.8 \mathrm{~kg})$ & $139-169 \mathrm{lb}-(63-76.6 \mathrm{~kg})$ \\
\hline $5^{\prime} 9^{\prime \prime} \cdot(175 \mathrm{~cm})$ & 131 - $160 \mathrm{lb}$ - $(59.4-72.6 \mathrm{~kg})$ & $144-176 \mathrm{lb}-(65.3-79.8 \mathrm{~kg})$ \\
\hline $5^{\prime} 10^{\prime \prime}-(178 \mathrm{~cm})$ & $135-165 \mathrm{lb}-(61.2-74.8 \mathrm{~kg})$ & $149-183 \mathrm{lb}-(67.6-83 \mathrm{~kg})$ \\
\hline $5^{\prime} 11^{\prime \prime}-(180 \mathrm{~cm})$ & $140-171 \mathrm{lb}-(63.5-77.5 \mathrm{~kg})$ & 155 - $189 \mathrm{lb}-(70.3-85.7 \mathrm{~kg})$ \\
\hline $6^{\prime} 0^{\prime \prime}-(183 \mathrm{~cm})$ & $144-176 \mathrm{lb}-(65.3-79.8 \mathrm{~kg})$ & $160-196 \mathrm{lb}-(72.6-88.9 \mathrm{~kg})$ \\
\hline $6^{\prime} 1^{\prime \prime}-(185 \mathrm{~cm})$ & $149-182 \mathrm{lb}-(67.6-82.5 \mathrm{~kg})$ & $166-202 \mathrm{lb}-(75.3-91.6 \mathrm{~kg})$ \\
\hline $6^{\prime} 2^{\prime \prime} \cdot(188 \mathrm{~cm})$ & $153-187 \mathrm{lb}-(69.4-84.8 \mathrm{~kg})$ & $171-209 \mathrm{lb}-(77.5-94.8 \mathrm{~kg})$ \\
\hline $6^{\prime} 3^{\prime \prime}-(191 \mathrm{~cm})$ & 158 - $193 \mathrm{lb}-(71.6-87.5 \mathrm{~kg})$ & $176-216 \mathrm{lb}-(79.8-98 \mathrm{~kg})$ \\
\hline $6^{\prime} 4^{\prime \prime}-(193 \mathrm{~cm})$ & $162-198 \mathrm{lb}-(73.5-89.8 \mathrm{~kg})$ & $182-222 \mathrm{lb}-(82.5-100.6 \mathrm{~kg})$ \\
\hline $6^{\prime} 5^{\prime \prime}-(195 \mathrm{~cm})$ & $167-204 \mathrm{lb}-(75.7-92.5 \mathrm{~kg})$ & $187-229 \mathrm{lb}-(84.8-103.8 \mathrm{~kg})$ \\
\hline
\end{tabular}

Fig. 6: Sample of the database after preprocessing

VitalSigns table consists of below fields.

- Id - This is the primary key of the table

- patientID - This is the foreign key of the table and this is refereeing the patientID of the patient table.

- Pulse - Pulse rate (/min)

- Systolic - The amount of Systolic pressure. (mmHg)

- Diastolic - The amount of Systolic pressure. (mmHg)

- Pp - Pulse pressure. This is calculated by subtracting value of Diastolic from the value of Systolic. ( $\mathrm{mmHg}$ )

- Pcv - Packed cell volume. This is called as Haematocrit (HCT) $(\%)$.

- Wcc - White Cell Count

- Plt - Platelet Count (x103/uL)

- urineOutput - Urine Output ( $\mathrm{ml} / \mathrm{kg} / \mathrm{hr}$ )

- fluidIntake - amount of total fluid intake ( $\mathrm{ml} / \mathrm{kg} / \mathrm{hr})$

- hours - Number of hours of the patient from the hospitalized time

- bodyTemp - Body temperature (Celsius) at each hour

- respiratoryRate - Respiratory rate at each hour

- oralIn - Oral fluid intake at each hour

- IVin - Amount of IV fluid at each hour

- capilaryRefilling - Capillary Refilling time

- IVType - Type of IV fluid whether it is normal saline, full bolus, half bolus of Dextran

- criticalhour - If the patient is on or was in critical phase, number of hours $n$ critical phase. When the WCC is decreasing and next increasing with the decreasing of platelet count, this is the startup point of the critical phase.

This module was implemented by using Entity Framework with MS SQL database. A sample is shown in Fig. 6 after the appropriate preprocessing.

\section{A. Implementation of the Analytic Model}

Analytic Module is a major part of this research. This Model is developed by using Cases Based Reasoning process. The initial module is retrieved by using a practical scenarios by consulting doctors. This module is consisting of cases and rules for every case. Reuse the cases to solve the problem with the known dataset.

Cases and rules are revised if necessary and retrain the new module as part of the new case(s) or rule(s). Below are the created cases and rules (Table II). 
Table II: Finalized cases from the analytics module

\begin{tabular}{|c|c|}
\hline Case & Rules \\
\hline 1. Dengue Fever Phase & $\begin{array}{ll}\text { - } & \text { WCC is decreasing } \\
\text { - } & \text { Platelets count is not decreasing than } 150,000\end{array}$ \\
\hline 2. Early DHF Phase & $\begin{array}{ll}\text { - } & \text { Platelet count is decreasing but above } 100,000 \\
\text { - } & \text { White Cell count is decreasing }\end{array}$ \\
\hline $\begin{array}{l}\text { 3. Possible of leaking Phase or the } \\
\text { critical stage }\end{array}$ & $\begin{array}{ll}\text { - } & \text { Platelet count is less than } 100,000 \\
\text { - } & \text { White Cell Count (WCC) is increasing after decreasing }\end{array}$ \\
\hline 4. Critical Phase (Leaking Phase) & $\begin{array}{l}\text { - Platelet count is decreasing than } 100,000 \text { or maintaining below } 100,000 \\
\text { - White Cell Count (WCC) is increasing } \\
\text { - } \quad \text { Pulse pressure is less than } 30 \\
\text { - } \quad \text { Increasing the PCV } \\
\text { - UO is decreasing } \\
\text { - Capillary refilling time is more than } 2 \text { seconds }\end{array}$ \\
\hline 5. Bleeding Phase & $\begin{array}{l}\text { - } \quad \text { Pulse pressure is decreasing } \\
\text { - } \quad \text { PCV is decreasing (20\%) or static (in the period of PCV should increase) } \\
\text { - } \quad \text { Capillary refilling time is decreasing } \\
\text { - } \quad \text { Urine Output is decreasing }\end{array}$ \\
\hline 6. Recovery Phase & $\begin{array}{ll}\text { - } & \text { Platelet count is increasing by } 5000 \\
\text { - } & \text { Urine Output is increasing } \\
\text { - } & \text { Stabilization of PCV }\end{array}$ \\
\hline
\end{tabular}

\section{SOME COMMON MISTAKES}

For the evaluation of results, the set of sample data was inserted into the system database and tested the actual results with expected results [16]. To test the CBR process, a sample set of vital signs data was gathered from Centre for Clinical Management of Dengue and Dengue Haemorrhagic Fever at District General Hospital, Negombo feed to the system and verified each case with the expected results as it is shown in Table III. Server application was hosted in localhost and Client and server with the same machine is used to test the user interface stability and to check the outputs were correct.

Table III: Evaluation Results

\begin{tabular}{|l|c|c|}
\hline & $\begin{array}{c}\text { Number of } \\
\text { Actual vital } \\
\text { signs Records }\end{array}$ & $\begin{array}{c}\text { Number of which } \\
\text { give expected } \\
\text { results }\end{array}$ \\
\hline Early DHF Phase & 30 & 30 \\
\hline $\begin{array}{l}\text { Possible of leaking } \\
\text { Phase or the critical } \\
\text { stage }\end{array}$ & 20 & 15 \\
\hline $\begin{array}{l}\text { Critical Phase } \\
\text { (Leaking Phase) }\end{array}$ & 15 & 10 \\
\hline $\begin{array}{l}\text { Possible Bleeding } \\
\text { Phase }\end{array}$ & 10 & 5 \\
\hline $\begin{array}{l}\text { Possible of Recovery } \\
\text { Phase }\end{array}$ & 100 & 20 \\
\hline Summary & 25 & 80 \\
\hline
\end{tabular}

The evaluation results show that this approach can use to predict the correct case, with approximately $80 \%$ percent accuracy.

\section{REFERENCES}

1. "Disease Outbreak News," World Health Organization, 2017.

2. M. o. H. -. S. Lanka, in Guidelines on Management of Dengue Fever \& Dengue Haemorrhagic Fever In Adults, Epidemiology Unit, Ministry of Health, p. 49, 2012.

3. S. Yacoub and B. Wills, "Dengue: an update for clinicians working in," in Clinical Medicine, pp. 82-85, 2015.

4. Management of Dengue Infection in Adults(3rd edition), Malaysia Health Technology Assessment Section (MaHTAS), 2015.
5. D. Alojado, "The Season For Dengue: What is Dengue Fever?," 25 August 2016. [Online]. Available: https://infocentraleph.blogspot.com/2016/08/the-season-for-dengue-wh at-is-dengue.html.

6. D. J. E. Jacob," "DENGUE PROTOCOL FOR MANAGEMENT," in DENGUE PROTOCOL, Department of Child Health, Christian Medical College, Vellore, pp. 40-50, 2015.

7. S. M. Wang and S. D. Sekaran, "Early Diagnosis of Dengue Infection Using a Commercial Dengue Duo Rapid Test Kit for the Detection of NS1, IGM, and IGG," Department of Medical Microbiology, Faculty of Medicine, University of Malaya, Kuala Lumpur, Malaysia , 2010.

8. S. Nubenthan and C. Shalomy, "A Wireless Continuous Patient Monitoring System for Dengue: Wi-Mon," in 2017 6th National Conference on Technology and Management(NCTM), Malabe, Sri Lanka, 2017.

9. N. b. M. Zainee and K. Chellappan, "A Preliminary Dengue Fever Prediction Model Based On Vital Signs And Blood Profile," in IEEE EMBS Conference on Biomedical Engineering and Sciences (IECBES), 2016.

10. D. Saikia and J. C. Dutta, "Early Diagnosis of Dengue Disease Using Fuzzy Inference System," in International Conference on Microelectronics, Computing and Communications (MicroCom), 2016.

11. M. S. Hossain and I. B. Habib, "A Belief Rule based Expert System to Diagnose Dengue Fever under Uncertainty," in Computing Conference 2017, London, UK, 2017.

12. M. Pantic, "Introduction to Machine Learning \& Case-Based Reasoning," Computing Department,Imperial College London, London.

13. Y. Avramenko, N. Lars and K. Andrzej , "Selection of Internals for Reactive Distillation Column-Case-based Reasoning Approach," Department of Chemical Technology, Lappeenranta University of Technology, Lappeenranta, 2002.

14. disabled-world.com, "Adult Male and Female Height to Weight Ratio Chart," disabled-world.com, 3011 2017. [Online]. Available: https://www.disabled-world.com/calculators-charts/height-weight.php. [Accessed 3009 2018].

15. L. T, V. S. Asirvadam2 and S. C. Daas, "Predicting Localized Dengue Incidences using Ensemble System Identification," in International Conference on Computer, Control, Informatics and Its Applications, Malaysia., 2015.

16. J. E. Jacob, V. Varghese, W. Rose and D. Adhikari, "DENGUE PROTOCOL FOR MANAGEMENT," in DENGUE - PROTOCOL, Department of Child Health, Christian Medical College, Vellore, pp. 40-50, 2015. 


\section{Authors Profile}

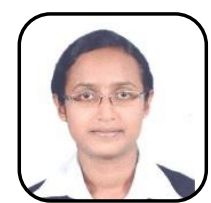

Samarasinghe Harshika Udani Briyatis is a Masters student in the Department of Information Technology, Faculty of Information Technology, University of Moratuwa Sri Lanka. She obtained her Bachelor of Computer Science from the University of Colombo School of Computing, Sri Lanka in 2012. She will graduate with Master of Science in Information Technology in 2019. Her research concentrates on Data mining.

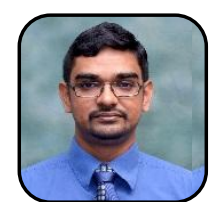

Saminda Chandika Premaratne is a senior lecturer in the Department of Information Technology, Faculty of Information Technology, University of Moratuwa Sri Lanka. He obtained his B.Sc. in Computer Science from the American University of Asia in 2002 and obtained his M.Phil. in 2008 from University of Colombo School of computing. Currently, conducting his Ph.D. studies in Malaysia University of Science and Technology. His research interests are Data mining, Video processing, and multimedia information retrieval. He has published his research work in several conferences and journals. There are several postgraduate researches carried under his supervision in the areas of data mining and multimedia systems.

D.G.Harendra De Silva Qualified MBBS from the University of Colombo with honours, obtained MRCP (Paediatrics) 1981 MSc Birmingham by thesis. He is a Commonwealth Scholar and Fellow. A Clinician, who described many diseases for the first time in Sri Lanka and some in Asia. The description of the cause of Haemolytic Uremic Syndrome (HUS) in Shigella shiga dysentery as due to cytokines and the postulate of the pathogenesis by showing local production of cytokines in the gut, for the first time in the world is credited to him as the lead author. Described Child abuse in Sri Lanka for the first time, was chairman of the Task Force on Child Abuse and the founder chairman of the statutory body, the National Child Protection Authority (NCPA). He also described for the first time in the world that conscription of children in war is child abuse and described another new definition of child abuse: "Suicide by Proxy". He had a Continuous University Teaching Career of over 38 years starting as Senior Lecturer Paediatrics at the University of Ruhuna from 1983-90, Associate Professor 90-92, Chair Professor 92-99, Chair senior/Professor University of Kelaniya 1999-2015, Chair Senior Professor University of Kelaniya 2015-17 and He now is presently Emeritus Professor of Paediatrics, University of Colombo and President SLMC. The Most Outstanding Asian Paediatrician, Award by the Asian Paediatrics Association (APPA) 2003, Senior Ashoka Fellow for Social Entrepreneurship by the Ashoka Foundation, (Wash DC), Distinguished Career award by the International Society against Child Abuse and Neglect (ISPCAN) and the CVCD (Committee of Vice Chancellors and Directors) award for most outstanding research in Medicine (2008) in the Universities in Sri Lanka. He was Honoured Vidyajyothi for "for outstanding scientific and technological achievements" by the Government of Sri Lanka. He has published about 100 papers. 